\title{
Experimental host-induced selection in Schistosoma mansoni strains from Guadeloupe and comparison with natural observations
}

\author{
PHILIPPE BRÉMOND,* NICOLE PASTEUR, † CLAUDE COMBES, FRANÇOIS RENAUD $\ddagger$ \& \\ ANDRE THÉRON
}

Laboratoire de Biologie Animale, URA 698 CNRS, Centre de Biologie Tropicale, Université, Av. de Villeneuve, 66860 Perpignan Cedex, tGénétique et Environnement, Institut des Sciences de l'Evolution, URA 327 CNRS, Université de Montpellier II, Place E. Bataillon, 34095 Montpellier Cedex, 5, and $\$$ Laboratoire de Parasitologie Comparée, URA 698 CNRS, Université de Montpellier II, Place E. Bataillon, 34095 Montpellier Cedex 5, France

\begin{abstract}
Allelic frequency variation at the malate dehydrogenase (E.C.1.1.1.37) polymorphic locus $(M d h-1)$ was analysed during several successive generations in four strains of Schistosoma mansoni from Guadeloupe, maintained experimentally on mice. A rapid evolution of the frequency of the Mdh-1a allele is interpreted as being the result of an interaction between experimental drift and selection induced by the murine laboratory host. These experimental results are compared to the genetic structures observed among the corresponding natural populations of $S$. mansoni in Guadeloupe (West Indies). They strengthen the hypothesis of a natural host-induced selection by the murine host (Rattus rattus), which, in Guadeloupe, plays the role of host reservoir for this human schistosome.
\end{abstract}

Keywords: enzymatic polymorphism, host selection, parasite, random drift, Rattus rattus, Schistosoma mansoni.

\section{Introduction}

Developments and improvements in population genetics methodologies (isoenzyme electrophoresis) have contributed to the realization of studies of polymorphism and gene flow within and between populations of schistosomes, parasites of mammal blood systems, by offering the possibility of individual analyses of these platyhelminths (see Rollinson, 1984). Research carried out on Schistosoma mansoni, which parasitize man and are responsible for schistosomiasis, has disclosed the existence of little geographical intraspecific divergence between strains from different endemic areas: Africa, Southwest Asia, South America and the West Indies (Fletcher et al., 1981; Boissezon \& Jelnes, 1982). The low genetic distances observed between all $S$. mansoni strains suggests that little intraspecific differentiation has occurred even between African and American populations of schisto-

Correspondence: André Théron, Laboratoire de Biologie Animale, URA 698 CNRS, Centre de Biologie Tropicale, Université, Av. de Villeneuve, 66860 Perpignan Cedex, France.

*Present address: Laboratoire des Schistosomiases, CERMES (OCCGE/ORSTOM). BP 10887. Niamey. République du Niger. somes. The recent isolation between $S$. mansoni from the Old and the New World, less than 400 years ago via the Slave Trade, may be an explanation for the little divergence observed (Combes, 1990). However, for the human schistosome species, worms are not directly accessible and analyses have been carried out exclusively on adult schistosomes obtained experimentally from laboratory-maintained strains, sometimes after several generations. Several authors (Fletcher, et al., 1981; Wright \& Ross, 1983; Rollinson, 1984; Kruger, 1989) have raised the question of a possible modification of the genetic structure of schistosome strains due to their experimental conditions of maintenance and hence, the representativity of these strains for the natural populations sampled. Bottlenecks occurring at the extraction phase, or at each experimental infection step, have been proposed as an explanation for the low genetic variability observed between the $S$. mansoni strains. As schistosome strains are maintained experimentally on laboratory vertebrate hosts different from the natural host, a differential host-induced selection may be also responsible for a modification in the genomic structure (Fletcher et al., 1981; LoVerde et al., 1985). 
Host-induced selection in natural populations of parasites is poorly documented. The demonstration of this phenomenon requires particular ecological and epidemiological conditions where the dynamics of a parasite population would be regulated by two different vertebrate hosts. Such a situation has been documented to occur within an insular focus of intestinal schistosomiasis (Guadeloupe, West Indies), where $S$. mansoni infects not only man but also a wild murine host (Rattus rattus), which plays the role of a host reservoir (Combes et al., 1975; Imbert-Establet, 1982). Genetic variability studies, carried out on: egg structure (Théron, 1986), cercarial chronobiology (Théron, 1984; Chassé \& Théron, 1988) and enzyme polymorphism (Rollinson et al., 1986; Théron et al., 1989) show genetic divergence between the populations sampled from different transmission sites of this focus. Théron et al. (1989) have pointed out a positive relationship for enzyme polymorphism between high frequencies in parasite populations of one (Mdh-1a) of the two alleles at one locus of malate dehydrogenase (MDH, E.C.1.1.1.37) and the part played by the murine reservoir host in the transmission dynamics. This correlation has been interpreted to the result of a possible natural host-induced selection. In order to test this hypothesis, we have investigated the allelic frequency variations at the $M d h-l$ locus in four strains of S. mansoni from Guadeloupe (established from human or murine natural hosts and collected from different ecological transmission sites) when maintained experimentally on a laboratory murine host (SWISS OF1 mice) during several generations.

\section{Materials and methods}

The four strains (Gh 2, Gm 8, Gm 7 and $\mathrm{Gm} 4$ ) of $S$. mansoni from Guadeloupe $(G)$ were extracted from eggs collected either from a natural human (h) host, or from a natural murine $(\mathrm{m})$ host (Rattus rattus). The strain Gh 2 was extracted from the stools of a human patient living in Sainte Rose (urban transmission site); the corresponding founder worm population was not accessible in this case. The strains Gm 8 and Gm 7 were extracted each from eggs obtained in the liver of a $R$. rattus trapped respectively in Labithie and Raizet (suburban transmission sites), which had natural founder worm populations of 33 males, 19 females (Gm 8) and 26 males, 13 females (Gm 7). The strain $\mathrm{Gm} 4$ was extracted from eggs obtained in the liver of a $R$. rattus trapped in Grand Etang (forest transmission site), which had a natural founder worm population of 26 males and 13 females. The strains $\mathrm{Gh} 2, \mathrm{Gm} 8, \mathrm{Gm}$ 7 and Gm 4 were then experimentally maintained for five (Gh 2.1 to Gh 2.5 ), four, seven and six generations, respectively, on Biomphalaria glabrata snails from Guadeloupe and on SWISS OF1 white mice. Individual schistosome sample preparation, isoelectric focusing on $0.5-\mathrm{mm}$ thick polyacrylamide gels and staining of MDH activity were carried out according to the method described by Brémond et al. (1989). As previously shown by Rollinson et al. (1989), two loci, $M d h-1$ and $M d h-2$, were recognized. The $M d h-2$ locus is monomorphic, whereas $M d h-1$ is polymorphic with two alleles Mdh-1a and Mdh-1b.

Three phenotypes were identified for the $M d h-1$ locus, related to two homozygote genotypes Mdh-1a/ Mdh-1a (AA : major activity at $\mathrm{pH}$ 6.4) and Mdh-1b/ Mdh-1b (BB : major activity at $\mathrm{pH} 7.2$ ), and one heterozygote genotype Mdh-1a/Mdh-1b (AB : major activity at $\mathrm{pH}$ 6.4, 6.8 and 7.2), whose three-banded pattern is indicative of a dimeric enzyme.

Given that experimental cross-breeding between male and female homozygote schistosomes of different genotypes (Théron et al., 1989) has confirmed the Mendelian inheritance of the two alleles at the $M d h-1$ locus, the electrophoretic data were treated in terms of allelic frequencies.

For each strain and at every generation (except $\mathrm{Gm}$ 2.3, Gm 7.1 and Gm 7.3, Gm 4.1, Gm 4.2 and $\mathrm{Gm} 8.2$ ), a sample of the schistosome population was collected from the mice (Table 1), to determine the frequency of the Mdh-1a allele $[\mathrm{f}(\mathrm{a})]$.

The allelic frequencies of Mdh-1a corresponding to the natural founder populations in murine hosts (Gm 8.0, Gm 7.0 and Gm 4.0, Tab. 2; Rollinson et al., 1986) were calculated from samples of schistosomes taken directly from wild $R$. rattus when the corresponding strains were established. It was impossible to have access to the original population for the strain with human origin (Gh 2 ), so the starting value of $f(a)$ is unknown. We therefore used the frequency obtained during the first parasite generation on the mouse as the starting frequency of the allele Mdh-1a (Table 2). Statistical comparisons between wild and experimental frequencies of the Mdh-1a allele for each line were made using the Chi-square test.

\section{Results}

Table 1 presents the number of schistosomes analysed and calculated frequencies of the Mdh-1a allele, both at each generation and globally, for the four strains of $S$. mansoni from Guadeloupe.

The results obtained on the murine schistosome strains Gm 8, Gm 7 and Gm 4 show an irregular modification of the allelic frequencies at the $M d h-l$ locus during the period of experimental maintenance of the parasite on mouse. However, in the three strains there 
is always an increase in the Mdh-1a allele frequency as compared to the founder populations. The difference $[\Delta f(a)]$ between Mdh-1a frequencies (Table 2) is low and not significant for the Gm 8 strain $[\Delta \mathrm{f}(\mathrm{a})=0.06]$ but is more marked for the $\operatorname{Gm} 7[\Delta \mathrm{f}(\mathrm{a})=0.16]$ and $\mathrm{Gm} 4[\Delta \mathrm{f}(\mathrm{a})=0.42]$ strains and significant at the 5 per cent level. For the strain of human origin (Gh 2 ), whose value of $f(a)$ is unknown for the natural population, the proportion of the Mdh-1a allele (Table 2 ) is very small $[f(a)=0.04]$ in the sample of worms corresponding to the first experimental generation (Gh 2.1) and zero in the following generations $[\Delta f(a)=-0.04]$.

\section{Discussion}

Maintaining $S$. mansoni strains on mice for four to seven generations has led to modifications to the genetic polymorphism. The rapid evolution of the fre-

Table 1 Evolution of the Mdh-1a allele frequencies during the successive experimental passages on mice of the human (Gh 2$)$ and the three murine strains (Gm 8, Gm 7 and Gm 4) of Schistosoma mansoni

\begin{tabular}{|c|c|c|c|c|c|c|}
\hline \multirow{2}{*}{$\begin{array}{l}\text { Strains and } \\
\text { generations }\end{array}$} & \multirow{2}{*}{$\begin{array}{l}\text { Worms } \\
\text { collected }\end{array}$} & \multirow{2}{*}{$\begin{array}{l}\text { Worms } \\
\text { examined }\end{array}$} & \multicolumn{3}{|c|}{ Mdh-1 genotypes } & \multirow{2}{*}{$\begin{array}{l}\text { Mdh-1a } \\
\text { frequencies }\end{array}$} \\
\hline & & & AA & $\mathrm{AB}$ & BB & \\
\hline Gh $2.1^{*}$ & 176 & 176 & 0 & 14 & 162 & 0.04 \\
\hline Gh 2.2 & 30 & 10 & 0 & 0 & 10 & 0 \\
\hline Gh 2.4 & 421 & 88 & 0 & 0 & 88 & 0 \\
\hline Gh 2.5 & 70 & 29 & 0 & 0 & 29 & 0 \\
\hline $\mathrm{Gm} 8.0^{*}$ & 52 & 39 & 0 & 12 & 27 & 0.15 \\
\hline Gm 8.1 & 259 & 133 & 6 & 37 & 90 & 0.18 \\
\hline Gm 8.3 & 53 & 36 & 0 & 3 & 33 & 0.04 \\
\hline $\mathrm{Gm} 8.4$ & 193 & 139 & 0 & 77 & 62 & 0.28 \\
\hline $\mathrm{Gm} 7.0^{*}$ & 58 & 47 & 1 & 21 & 25 & 0.24 \\
\hline $\mathrm{Gm} 7.2$ & 110 & 68 & 3 & 40 & 25 & 0.34 \\
\hline $\mathrm{Gm} 7.4$ & 139 & 58 & 3 & 39 & 16 & 0.39 \\
\hline $\mathrm{Gm} 7.5$ & 75 & 57 & 0 & 40 & 17 & 0.35 \\
\hline $\mathrm{Gm} 7.6$ & 80 & 77 & 12 & 35 & 30 & 0.38 \\
\hline $\mathrm{Gm} 7.7$ & 242 & 117 & 24 & 60 & 33 & 0.46 \\
\hline $\mathrm{Gm} 4.0^{*}$ & 39 & 25 & 6 & 5 & 14 & 0.34 \\
\hline $\mathrm{Gm} 4.3$ & 119 & 51 & 31 & 20 & 0 & 0.80 \\
\hline Gm 4.4 & 139 & 41 & 13 & 20 & 8 & 0.56 \\
\hline Gm 4.5 & 109 & 69 & 54 & 15 & 0 & 0.89 \\
\hline $\mathrm{Gm} 4.6$ & 142 & 99 & 45 & 54 & 0 & 0.73 \\
\hline
\end{tabular}

*Natural founder infrapopulations (data from Rollinson et al., 1986).

Table 2 Differences $[\Delta f(a)]$ between Mdh-1 a allelic frequencies observed on the natural founder infrapopulations (data from Rollinson et al., 1986) of Schistosoma mansoni and their corresponding laboratory strains maintained on mice (this study)

\begin{tabular}{|c|c|c|c|c|c|c|c|}
\hline \multicolumn{3}{|c|}{ Natural infrapopulation } & \multicolumn{3}{|c|}{ Laboratory strains } & \multirow{2}{*}{$\begin{array}{l}\text { Difference } \\
\Delta \mathrm{f}(\mathrm{a})\end{array}$} & \multirow{2}{*}{$\begin{array}{l}\chi^{2} \\
\mathrm{df}=1\end{array}$} \\
\hline Code & Sample & $f(a)$ & Code & Sample & $f(a)$ & & \\
\hline Gh 2.1 & 176 & 0.04 & Gh 2 & 127 & 0 & -0.04 & $14.04^{* *}$ \\
\hline $\mathrm{Gm} 8.0$ & 39 & 0.15 & $\mathrm{Gm} 8$ & 308 & 0.21 & +0.06 & $1.32 \mathrm{~ns}$ \\
\hline $\mathrm{Gm} 7.0$ & 47 & 0.24 & $\mathrm{Gm} 7$ & 377 & 0.40 & +0.16 & $8.05^{* *}$ \\
\hline $\mathrm{Gm} 4.0$ & 25 & 0.34 & $\mathrm{Gm} 4$ & 260 & 0.76 & +0.42 & $40.09^{* *}$ \\
\hline
\end{tabular}

*Significant differences at $P<0.01$ with a chi-square test. 
quency of the Mdh-1a allele, must be interpreted as being the result of random drift or selection, or a combination of both.

Experimental drift can explain the disappearance, as early as the second generation, of the Mdh-1a allele in the strain of schistosomes of human origin (Gh 2), since this allele was probably very rare in the original infrapopulation $[\mathrm{f}(\mathrm{a})=0.04$ in the first experimental generation Gh 2.1]. Random drift is very likely to occur under the conditions in which parasite strains are maintained in the laboratory. Indeed, each step of the experimental cycle [sampling eggs in mouse, limited number of snails infected at each passage, massive production of cercariae originating from only a few developed miracidia, small recovery level of adult schistosomes (32.5 per cent) and a biased sex ratio, 2.64] results in a significant reduction in the effective size of $S$. mansoni infrapopulations, and consequently in the genetic variability of the strains studied. The bottlenecks caused by the parasite's successive passages on the experimental hosts should hinder the least frequent allele.

On the contrary, the evolution of allelic frequencies in the three strains of $S$. mansoni of murine origin (Gm 8, Gm 7 and $\mathrm{Gm} \mathrm{4)}$ and the systematic increase in the frequency of Mdh-1a can only be explained by selection favourable to this allele. Indeed, this allele was systematically found to be at least frequent in each of the original populations of these strains. The strain $\mathrm{Gm} \mathrm{4,} \mathrm{whose} \mathrm{initial} \mathrm{frequency} \mathrm{of} \mathrm{Mdh-1a} \mathrm{was} \mathrm{higher}$ than that of strains $\mathrm{Gm} 8$ and $\mathrm{Gm} \mathrm{7,} \mathrm{shows} \mathrm{a} \mathrm{faster}$ evolution of the frequency of Mdh-1a which can be explained by the joint action of selection and experimental drift.

As the molluscs used in the laboratory have the same geographical origin as the natural intermediate hosts (B. glabrata), it is highly probable that the selection pressure in favour of Mdh-1a originates from the experimental murine host (the white mouse). Fortunately, our experimental results on $S$. mansoni from Guadeloupe can be compared with results previously obtained under the natural conditions of this parasite's transmission in different sites in Guadeloupe. Epidemiological surveys have shown that the part played by the murine reservoir host ( $R$. rattus) in the dynamics of $S$. mansoni populations was sometimes more significant and sometimes less significant than that played by man (Théron et al., 1992), depending on the ecological context (urban, suburban or forest areas) of the transmission sites. Thanks to the study of enzymatic polymorphism of the parasite populations originating from these various sites (Rollinson et al., 1986), and to its analysis as a function of eco-epidemiological data (Théron et al., 1989), it was possible to establish a significant positive correlation between the frequency of the allele Mdh-1a and the level of participation of $R$. rattus in maintaining the cycle of this anthropophilic parasite. The higher the participation of the rodent in the transmission dynamics of the parasite in a given site, the higher the allelic frequency of Mdh-1a in the schistosome population. Thus, our experimental results strengthen the hypothesis of host-induced selection by a definitive murine host different from the usual human host and once more raise the problem of the representativeness of results obtained on the biology, the physiology and the genetics of human parasites maintained on laboratory hosts.

The hypothesis of a possible experimental hostinduced selection on schistosome strains was first discussed by Fletcher et al. (1981) when they showed that a $S$. mansoni strain from Kenya passaged through mice displayed a much lower level of enzymatic polymorphism than when passaged through baboons. Later, LoVerde et al. (1985) compared the evolution of the allelic frequencies at four polymorphic loci encoding enzymes for a human strain of $S$. mansoni from Kenya, experimentally maintained at first on baboon then on mouse. These authors showed that the transfer from the primate host to the murine host was accompanied by modifications of the enzymatic polymorphism in the schistosome infrapopulations: a rapid disappearance of the least frequent alleles at the $G p i, P g m-2$ and $M d h-1$ loci and an increase in the frequency of the Mdh-2b allele. All these results concern human strains passaged on an experimental murine host. In our experiments, we show that even when originating from a natural murine host $(R$. rattus), which has exerted a selective pressure on schistosome populations, maintaining the parasite on an experimental murine host (white mice) still increases the frequency of the least frequent allele for the $M d h-1$ locus. These results suggest that among natural populations of $S$. mansoni from Guadeloupe, isolation between human and murine host-adapted populations is not achieved and that a gene flow, even reduced, limits the effects of the selective pressure of the rodents upon the parasite.

The modalities of the selection of the Mdh-1a allele by the murine host (whether experimental or natural) remain unknown. However, two hypotheses can be proposed.

(i) This allele confers by itself a better fitness on the schistosomes reproducing in rodents.

(ii) This allele is neutral towards the selection but linked to a selected gene.

Results of other studies favour the first hypothesis. Bout et al. (1978) identified the antigen ' 4 ' as one of the two MDH isoenzymes in S. mansoni from Porto-Rico. This antigen, whose $\mathrm{pH}_{\mathrm{i}}$ is 7.1, may correspond to our $M d h-1$ locus. Thus it may be envisaged that the murine 
host's immune response will be different depending on whether the schistosomes infesting it carry the Mdh-1a or the Mdh- $1 \mathrm{~b}$ allele.

Although they only concern a very small part of the genome, these results, together with those obtained on the morphological polymorphism of the parasites' eggs (Théron, 1986) and on the genetics divergences of cercarial shedding rhythms (Théron, 1984), show the significant effect any widening of the host spectrum may have on the evolutionary biology of these parasites (Combes, 1991).

\section{Acknowledgements}

This work received financial support from the UNDP World Bank WHO Special Programme for Research and Training in Tropical Diseases, the CNRS (Sciences de la Vie) and the ORSTOM (Département Santé). Special thanks are due to J.-B. Bergé and J.-M. Brides, from the INRA in Antibes, for their precious help.

\section{References}

BOISSEZON, B. AND JELNES, J. E. 1982. Isoenzyme studies on cercariae from monoinfections and adult worms of Schistosoma mansoni (10 isolates) and S. rodhaini (one isolate) by horizontal polyacrylamide gel electrophoresis and staining of eight enzymes. Z. Parasiten., 67, 185-196.

BOUT, D., DUPAS, H., CAPRON, M., EL GAZAWI, A., CARLIER, Y., DELACOURTE, A. AND CAPRON, A. 1978. Purification, immunochemical and biochemical characterization of malate dehydrogenase of Schistosoma mansoni. Immunochemistry. 15, 613-638.

BRÉMOND, P., THÉRON, A. AND ROLLINSON, D. 1989. Hybrids between Schistosoma mansoni and S. rodhaini: characterization by isoelectric focusing of six enzymes. Parasitol. Res., 76, 138-145.

CHASSÉ, J. L. AND THÉRON, A. 1988. An example of circular statistics in chronobiological studies : analysis of polymorphism in the emergence rhythms of Schistosoma mansoni cercariae. Chronobiol. Int, 5, 433-439.

COMBES, C. 1990. Where do human schistosomes come from? An evolutionary approach. Tree, 10, 334-337.

COMBES, C. 1991. Evolution of parasite life cycles. In: Toft, C. A., Aeschlimann, A. and Bolis, L. (eds) Parasite-host
Associations. Coexistence or Conflict? Oxford Science Publications, Oxford pp. 62-82.

COMBES, C., LÉGER, N. AND GOLVAN, Y. J. 1975. Le rôle du rat dans la dynamique de l'endémie schistosomienne en Guadeloupe. Comp. Rend. Acad. Sci. Paris., 281, Series D, 1059-1061.

FLETCHER, M., LOVERDE, P. T. AND WOODRUFF, D. S. 1981. Genetic variation in Schistosoma mansoni: enzyme polymorphisms in populations from Africa, Southwest Asia, South America and the West Indies. Am. J. Trop. Med Hyg., 30, 406-421.

IMBERT-ESTABLET, D. 1982. Infestation naturelle des rats sauvages par Schistosoma mansoni en Guadeloupe: Données quantitatives sur le développement et la fertilité du parasite. Ann. Parasitol., 57, 573-585.

KRUGER, F. J. 1989. Enzyme polymorphism in Schistosoma mattheei from cattle in the Eastern Transvaal Lowveld. $J$. Helminthol., 63, 191-196.

LOVERDE, P. T., DEWALD, J., MINCHELA, D. J., BOSSHARDT, S. C. AND DAMIAN, R. T. 1985. Evidence for host-induced selection in Schistosoma mansoni. J. Parasitol., 71, 297-301.

ROLLINSON, D. 1984. Recent advances in the characterisation of schistosomes of man and their intermediate host. Trop. Dis. Res. Series, 5, 401-441.

ROLLINSON, D., IMBERT-ESTABLET, D. AND ROSS, G. C. 1986. Schistosoma mansoni from naturally infected Rattus rattus in Guadeloupe : Identification, prevalence and enzyme polymorphism. Parasitology, 93, 39-53.

THÉRON, A. 1984. Early and late shedding patterns of Schistosoma mansoni cercariae: ecological significance in transmission to human and murine hosts. J. Parasitol., 70, 652-655.

THÉron, A. 1986. Polymorphisme des oeufs de Schistosoma mansoni dans le foyer guadeloupéen (Antilles Françaises): présence de ' $S$. rodhaini-like' parasites? Acta Trop., 43, 335-342.

THÉRON, A., BRÉMOND, P. AND IMBERT-ESTABLET, D. 1989. Allelic frequency variations at the Mdh-I locus within Schistosoma mansoni strains from Guadeloupe (French West Indies): ecological interpretation. Comp. Biochem. Physiol., 93, 32-37.

THÉRON, A., POINTIER, J. P., MORAND, S., IMBERT-ESTABLET, D. AND BOREL, G. 1992. Long-term dynamics of natural populations of Schistosoma mansoni among Rattus rattus in patchy environment. Parasitology, 104, 291-298.

WRIGHT, C. A. AND ROSS, G. C. 1983. Enzyme analysis of Schistosoma haematobium. Bull. World Health Organ., 61, 307-316. 